\title{
Pengukuran Sampel Magnetik Cair dengan Vibrating Sample Magnetometer (Vsm)
}
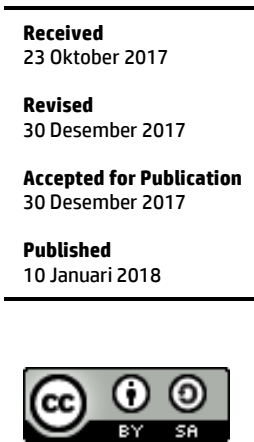

This work is licensed under a Creative Attribution ShareAlike 4.0 ShareAlike 4.0

\author{
W Z Lubis, Mujamilah \\ PSTBM-BATAN, Kawasan Puspiptek Serpong, Tangerang Selatan 15314 \\ "E-mail: wildan@batan.go.id
}

\begin{abstract}
This article discusses the performance of Vibrating Sample Magnetometer (VSM) Oxford $1.2 \mathrm{H}$ in characterizing the magnetic samples in liquid form. Samples of water-based ferrofluid placed in a capillary tube pipe. Measurement of samples with varied position, volume and concentration as well as repeated measurements are carried out to evaluate the performance. From these series of measurements, it brings that optimal volume range with measurement results that can still be accounted for is $10 \mu \mathrm{L}$, with samples being in equilibrium position within the pick-up coil. The smallest sample concentration which still can be observed quantitatively is $0.332 \mathrm{mg} / \mathrm{mL}$. Repeatability test gives the value of the magnetic moment deviation of $\sim 4 \%$. The accuracy of the sample preparation and positioning of the samples is analyzed being a major factor which causes this measurement error. In general it can be concluded that the liquid sample measurement will give better results when using reverse pipetting mode when putting the liquid samples within capillary tube using a micropipette. The measurement should be done as soon as possible after preparation.
\end{abstract}

Keywords: Vibrating sampel magnetometer (VSM), ferrofluid, volume, concentration, repeatibility

\begin{abstract}
Abstrak
Artikel ini membahas tentang unjuk kerja Vibrating Sample Magnetometer (VSM) Oxford $1.2 \mathrm{H}$ dalam mengkarakterisasi sampel magnetik dalam bentuk cair. Sampel cair berupa ferrofluid berbasis air ditempatkan dalam pipa kapiler tertutup. Posisi, volume dan konsentrasi sampel divariasikan serta dilakukan pengukuran berulang untuk menguji kedapat-ulangan (repeatibility). Dari serangkaian pengukuran yang dilakukan diperoleh bahwa range volume optimal dengan hasil pengukuran yang masih bisa dipertanggungjawabkan adalah $10 \mu \mathrm{L}$ dengan posisi sampel setimbang serta berada dalam daerah antara pick-up coil. Sedangkan konsentrasi terkecil yang masih dapat diamati secara kuantitatif adalah sampel dengan konsentrasi $0,332 \mathrm{mg} / \mathrm{mL}$. Uji kedapat-ulangan memberikan nilai penyimpangan momen magnetik total $\sim 4 \%$. Keakuratan penyiapan sampel dan penempatan sampel merupakan faktor utama penyebab penyimpangan. Secara umum dapat disimpulkan bahwa pengukuran sampel cair akan memberikan hasil yang lebih baik bila digunakan mode tekanan positif (reverse pipetting) pada saat memasukkan sampel cair dengan micropipette serta sampel sesegera mungkin diukur setelah preparasi
\end{abstract}

Kata Kunci: Vibrating sampel magnetometer (VSM), ferrofluid, volume, konsentrasi, kedapat-ulangan.

\section{Pendahuluan}

Penggunaan bahan magnetik dalam bentuk cair/koloid (ferrofluid) makin meningkat pada berbagai bidang. Secara umum ferrofluid didefinisikan sebagai suspensi koloid stabil dari nanopartikel magnetik yang tersebar dalam medium cair. Bahan ini mempunyai aplikasi yang luas mulai dari aplikasi sebagai pelumas pada sistem mekanis hingga aplikasi di bidang biomedis sebagai bahan pengontras MRI serta sebagai agen hipertermi [1][2]. Berbagai aplikasi ini mengeksplor beberapa sifat ferrofluid terutama sifat mudah-alir dan mudah-kendali nya dengan memanfaatkan medan 
magnet luar [3]. Untuk mengoptimasi perilaku kemagnetan pada berbagai bidang aplikasi ini, pemahaman tentang karakteristik magnetik bahan dalam bentuk cair (ferrofluid) akan menjadi data yang sangat penting.

Karakteristik magnetik suatu bahan biasanya diukur dari kurva histeresis magnetik hasil pengukuran dengan magnetometer. Beberapa tipe magnetometer komersial telah dapat dengan teliti dan akurat mengukur karakteristik magnetik untuk bahan dalam bentuk padatan maupun dalam bentuk serbuk. Untuk sampel cair, biasanya sampel akan dikeringkan terlebih dahulu sebelum pengukuran menghasilkan sampel dalam bentuk serbuk. Beberapa peneliti juga mencoba mengukur sampel cair tanpa pengeringan namun dengan menambahkan bahan pengental/pengikat (binder) yang memungkinkan diperolehnya sampel dalam bentuk utuh [4]. Perubahan ini dengan sendirinya tidak dapat menggambarkan secara akurat perilaku magetik sampel dalam kondisi cair.

Boekelheide dkk mencoba mengukur sampel cair secara in-situ dengan memodifikasi kondisi preparasi sampel dan mendapatkan bahwa ada beberapa artefak yang muncul selama pengukuran sampel cair yaitu adanya perubahan posisi tengah sampel selama pengukuran, perubahan bentuk serta perubahan distribusi nanopartikel magnetik dalam fluida [5]. Artefak-artefak ini dianalisis disebabkan adanya penyusunan ulang (re-arrangement) nanopartikel magnetik akibat medan magnetik ataupun aglomerasi akibat ketidakstabilan sampel fluida. Beberapa metoda untuk mengurangi artefak-artefak ini juga dibahas misalkan dengan upaya re-centering untuk tiap pengukuran maupun memastikan tidak adanya gelembung udara dalam sampel uji. Penelitian lain dilakukan dengan memodifikasi bentuk wadah sampel uji sehingga diperoleh pendekatan sampel berbentuk sferis untuk mengkoreksi faktor demagnetisasi dan memastikan kondisi isotropis selama pengukuran. Dengan modifikasi ini, memang diperoleh data yang lebih akurat, namun sangat bergantung tipe magnetometer yang digunakan (dalam penelitian ini digunakan VSM Lake Shore 7404) dengan harga wadah sampel termodifikasi yang cukup mahal serta dengan tingkat kesulitan preparasi sampel yang cukup tinggi [6].

Pada artikel ini dilakukan pengujian performa pengukuran sampel magnetik cair yang ditempatkan dalam wadah tabung gelas kapiler dan diukur menggunakan VSM (Vibrating Sample Magnetometer) OXFORD1.2H [7]. Tabung gelas kapiler ini bersifat sekali pakai (dispossable) dan berharga murah. Beberapa variasi pengukuran dilakukan untuk menguji tingkat kedapat-ulangan (repeatability), pengaruh volume, konsentrasi serta posisi sampel. Sampel cair yang digunakan adalah sampel cair (ferrofluid) dari nanopartikel magnetik $\mathrm{Fe}_{3} \mathrm{O}_{4}$ yang dimodifikasi permukaannya dengan $\mathrm{HNO}_{3}$ dan membentuk koloid stabil berbasis air.

\section{Metode Penelitian}

Secara prinsip, pada pengukuran sifat magnetik dengan VSM, sampel akan digetarkan arah vertikal pada sekitar titik tengah sistem koil pembaca tegangan dengan amplitudo tertentu. Tegangan yang terinduksi pada sistem koil akan sebanding dengan momen magnetik sampel uji. Untuk VSM OXFORD1.2H yang digunakan dalam penelitian ini, mempunyai skema daerah sampel sebagaimana ditampilkan pada Gambar 1 [7]. Sampel diharapkan berada dititik tengah dan setimbang dalam sistem 4 koil dengan jarak antar koil vertikal $8 \mathrm{~mm}$. Untuk menentukan posisi setimbang ini, dilakukan langkah kalibrasi posisi sebelum pengukuran kurva histeresis.

Selanjutnya untuk pengujian, sampel cair, ferrofluid berbasis air berisi nanopartikel $\mathrm{Fe}_{3} \mathrm{O}_{4}$ termodifikasi $\mathrm{HNO}_{3}$ dimasukkan ke dalam tabung gelas kapiler ( $\varnothing$ int.: $1,1-1,2 \mathrm{~mm} ; 1=75 \mathrm{~mm}$ ) menggunakan mikropipet dengan micro-tip tipe low-retention untuk memastikan tidak ada sampel yang tertinggal dalam tip. Pengisian sampel ini dilakukan baik dengan mode tekanan positif (reverse pipetting), dimana sampel dalam micro-tip melebihi volume yang akan diisikan, maupun dengan mode tekanan negatif (forward pipetting) dimana sampel dalam micro-tip sama dengan volume yang akan diisikan Selanjutnya tabung kapiler ditempatkan pada batang pemegang sampel/ sample probe VSM dan siap untuk diukur. Gambar 2 menampilkan foto sampel ferrofluid, asesori untuk preparasi sampel serta sampel yang siap diukur. 


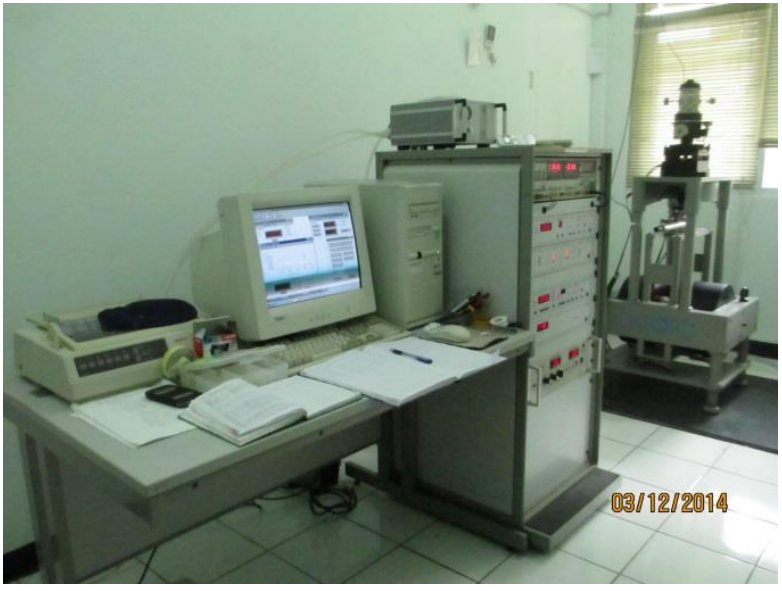

(a)

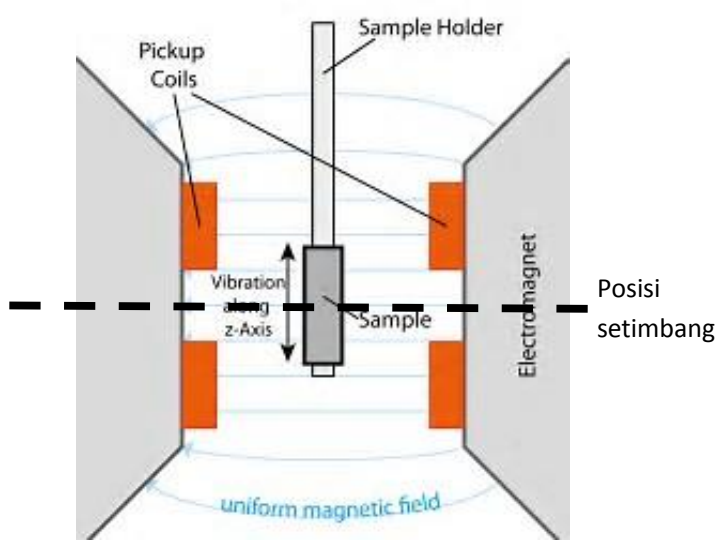

(b)

Gambar 1. (a) Foto fasilitas VSM OXFORD 1.2H di PSTBM-BATAN dan (b) skema area tempat sampel dengan konfigurasi koil pembaca data (pick-up coils)
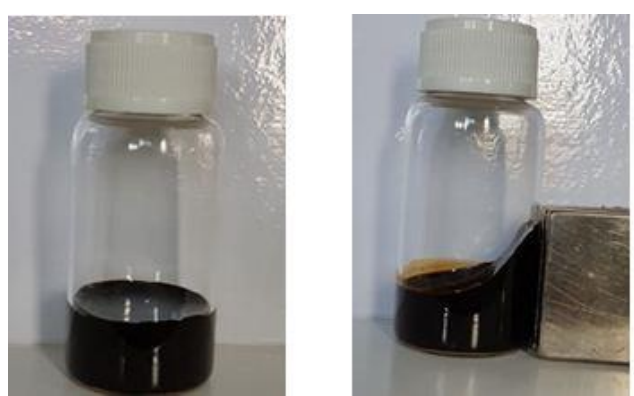

(a)

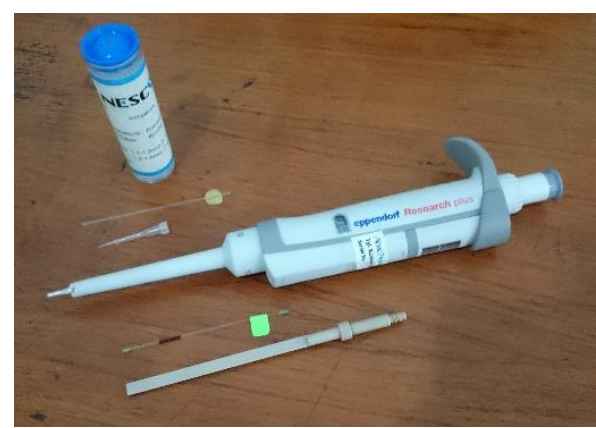

(b)

Gambar 2. (a) Foto sampel ferrofluid berbasis air yang tertarik oleh magnet dan (b) asesori preparasi sampel cair untuk pengukuran dengan VSM

Pengujian dilakukan dengan memvariasikan volume $\left(V_{n}\right)$, posisi sampel terhadap titik tengah $\left(P_{n}\right)$, serta uji kedapat-ulangan (repeatibility, $R_{n}$ ). Juga dilakukan uji stabilitas data sebagai fungsi waktu, $T_{n}$ dan variasi konsentrasi $\left(K_{n}\right)$. Pada setiap sampel dilakukan penimbangan untuk mendapatkan data massa sampel cair terukur $m_{\mathrm{u}}$, yang dihitung dengan persamaan :

$$
m_{\mathrm{u}}=m_{\mathrm{k}}^{\mathrm{i}}-m_{\mathrm{k}}^{\mathrm{o}},
$$

dengan $m_{\mathrm{u}}$ menyatakan massa sampel cair terukur; $m_{\mathrm{k}}^{\mathrm{i}}$ menyatakan massa tabung kapiler berisi sampel; $m_{\mathrm{k}}^{\mathrm{o}}$ menyatakan massa tabung kapiler kosong/tanpa sampel.

Data massa sampel cair teoritis atau terhitung $m_{t}$ merupakan gabungan antara massa medium cair dan massa nanopartikel magnetik di dalamnya, dihitung dengan menggunakan persamaan :

$$
\begin{gathered}
m_{\mathrm{t}}=m_{\mathrm{NPM}}-m_{\mathrm{a}} \\
m_{\mathrm{NPM}}=V_{\mathrm{s}} * \rho_{\mathrm{s}} \\
m_{\mathrm{a}}=V_{\mathrm{a}} * \rho_{\mathrm{a}}
\end{gathered}
$$




$$
V_{\mathrm{a}}=V_{\mathrm{s}}-V_{\mathrm{NPM}}=V_{\mathrm{s}}-\left(\frac{m_{\mathrm{NPM}}}{\rho_{\mathrm{NPM}}}\right) \text {, }
$$

dengan indeks NPM menyatakan nanopartikel magnetik dan a menyatakan air atau medium ferrofluid. Untuk nilai densitas $(\rho)$ air adalah $1 \mathrm{mg} / \mathrm{mL}$, densitas sampel adalah $41,5 \mathrm{mg} / \mathrm{mL}$ dan densitas nanopartikel magnetik adalah $5,18 \mathrm{~g} / \mathrm{mL}$ [8].

\section{Hasil dan Pembahasan}

Langkah proses pengujian dimulai dari penentuan titik tengah atau titik setimbang dari sistem koil yang dilakukan dengan mengambil data tegangan sebagai fungsi posisi sampel pada arah vertikal baik dalam arah turun maupun naik. Pada penentuan ini digunakan sampel kalibrator Ni. Grafik yang diperoleh ditampilkan pada Gambar 3, menunjukkan bahwa posisi setimbang ada di Zc $=13,4 \mathrm{~mm}$.

Pada tahap berikutnya dilakukan pengukuran sebagai fungsi variasi volume sampel. Gambar 4 menampilkan kurva histeresis untuk sampel cair dengan volume bervariasi dari 2,5 $\mu \mathrm{L}$ hingga $20 \mu \mathrm{L}$. Data massa sampel ditampilkan pada Tabel 1. Hasil pengukuran massa sampel dengan volume yang terlalu kecil atau terlalu besar akan memiliki simpangan yang cukup besar dibanding data perhitungan teori. Sedangkan sifat magnetiknya cenderung menunjukkan kenaikan nilai momen dengan naiknya volume hingga volume $15 \mathrm{~mL}$, dan selanjutnya nilai magnetisasi cenderung menurun dengan naiknya volume seperti yang ditampilkan pada Gambar 5. Hal ini dianalisis terkait dengan daerah deteksi pickup coil yang akan menurun dengan makin jauhnya posisi sampel dari posisi setimbang coil. Analisis lebih lanjut pada nilai momen magnetisasi yang dinormalisasi terhadap massa tertimbang (N) menunjukkan nilai $\mathrm{N}$ tertinggi dicapai pada volume $10 \mathrm{~mL}$. Dari data ini dapat disimpulkan bahwa volume optimal diperoleh untuk sampel dengan volume $10 \mathrm{~mL}$.

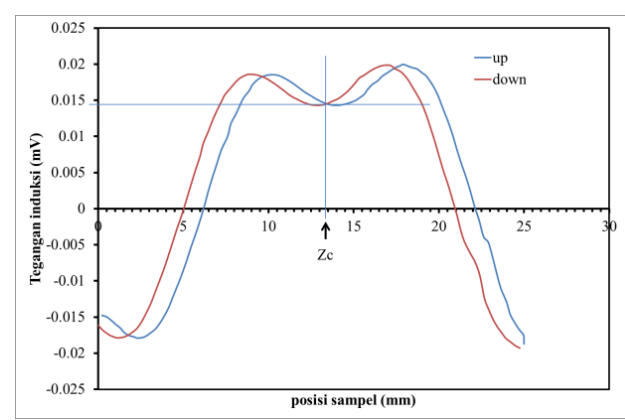

Gambar 3. Grafik tegangan induksi sebagai fungsi posisi sampel
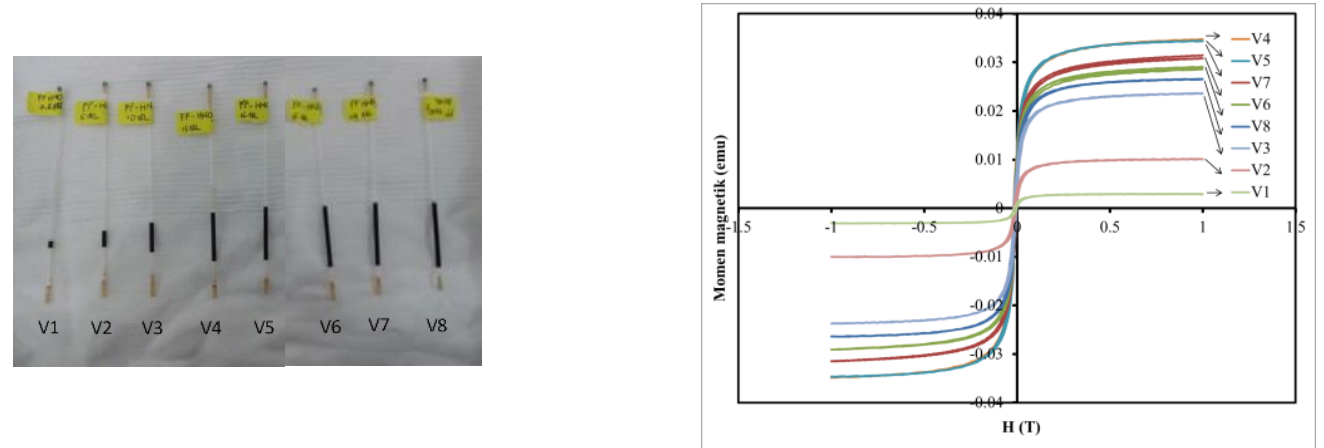

Gambar 4. Kurva histeresis sampel cair sebagai fungsi volume 
Tabel 1. Data nilai moment magnetic dan massa sampel cair dengan variasi volume

\begin{tabular}{|c|c|c|c|c|c|c|c|c|}
\hline Sampel & $V_{1}$ & $V_{2}$ & $V_{3}$ & $V_{4}$ & $V_{5}$ & $V_{6}$ & $V_{7}$ & $V_{8}$ \\
\hline Volume $(\mu \mathrm{L})$ & 2,5 & 5 & 10 & 15 & 16 & 18 & 19 & 20 \\
\hline $\begin{array}{c}\text { Massa terhitung, } \\
\mathbf{m}_{\mathrm{h}}(\mathbf{m g})\end{array}$ & 2,5838 & 5,1677 & 10,335 & 15,503 & 16,536 & 18,603 & 19,637 & 20,671 \\
\hline $\begin{array}{c}\text { Massa tertimbang, } \\
\mathbf{m}_{\mathrm{t}}(\mathbf{m g})\end{array}$ & 1,21 & 5,19 & 10,88 & 17,39 & 18,34 & 19,97 & 22,87 & 23,61 \\
\hline $\begin{array}{c}\text { Momen magnetik, } \\
\text { M (emu) }\end{array}$ & 0,0029 & 0,0101 & 0,0235 & 0,0345 & 0,0344 & 0,0291 & 0,0315 & 0,0266 \\
\hline $\begin{array}{c}N=M / m_{t} \\
(\text { emu/gram) }\end{array}$ & 34,988 & 60,374 & 70,114 & 68,596 & 64,119 & 48,257 & 49,348 & 39,568 \\
\hline
\end{tabular}

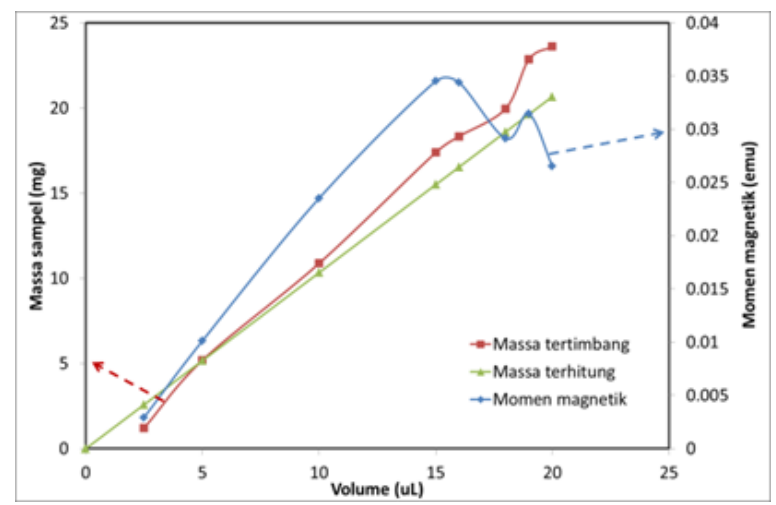

Gambar 5. Grafik perubahan momen magnetik dan massa sampel sebagai fungsi volume sampel

Selanjutnya dilakukan pengukuran kurva histeresis dari sampel cair pada tiga posisi, yaitu di posisi setimbang $\left(P_{1}=Z_{c}\right)$, posisi di bawah titik setimbang $\left(P_{2}<Z_{c}\right)$ dan di atas titik setimbang $\left(P_{3}>\right.$ $Z_{c}$ ) yang ditampilkan pada Gambar 6 . Volume sampel yang diukur adalah $10 \mu \mathrm{L}$. Data pada Gambar 6 menunjukkan bahwa perubahan posisi sampel akan mengakibatkan perubahan pada nilai magnetisasi saturasi. Mengacu pada pola kurva kalibrasi pada Gambar 3, maka perubahan ini dapat diartikan bahwa nilai magnetisasi terukur akan sebanding dengan nilai total tegangan yang terinduksi pada koil. Pada saat posisi sampel semakin jauh dari titik setimbang, maka nilai total tegangan induksi dapat menurun akibat mulai terjadinya induksi tegangan negatif pada koil sebagaimana tergambar pada kurva kalibrasi. Pola penurunan nilai magnetisasi akibat pergeseran posisi sampel juga ditemukan oleh peneliti lain [5]. Pergeseran ini juga dapat dikaitkan dengan adanya pelebaran "ukuran sampel" cair akibat pemisahan sampel cair selama pengukuran yang menjadikan posisi setimbang sampel bergeser. Pemisahan sampel ini dengan sendirinya akan melemahkan interaksi sampel dan menurunkan nilai magnetisasi. 

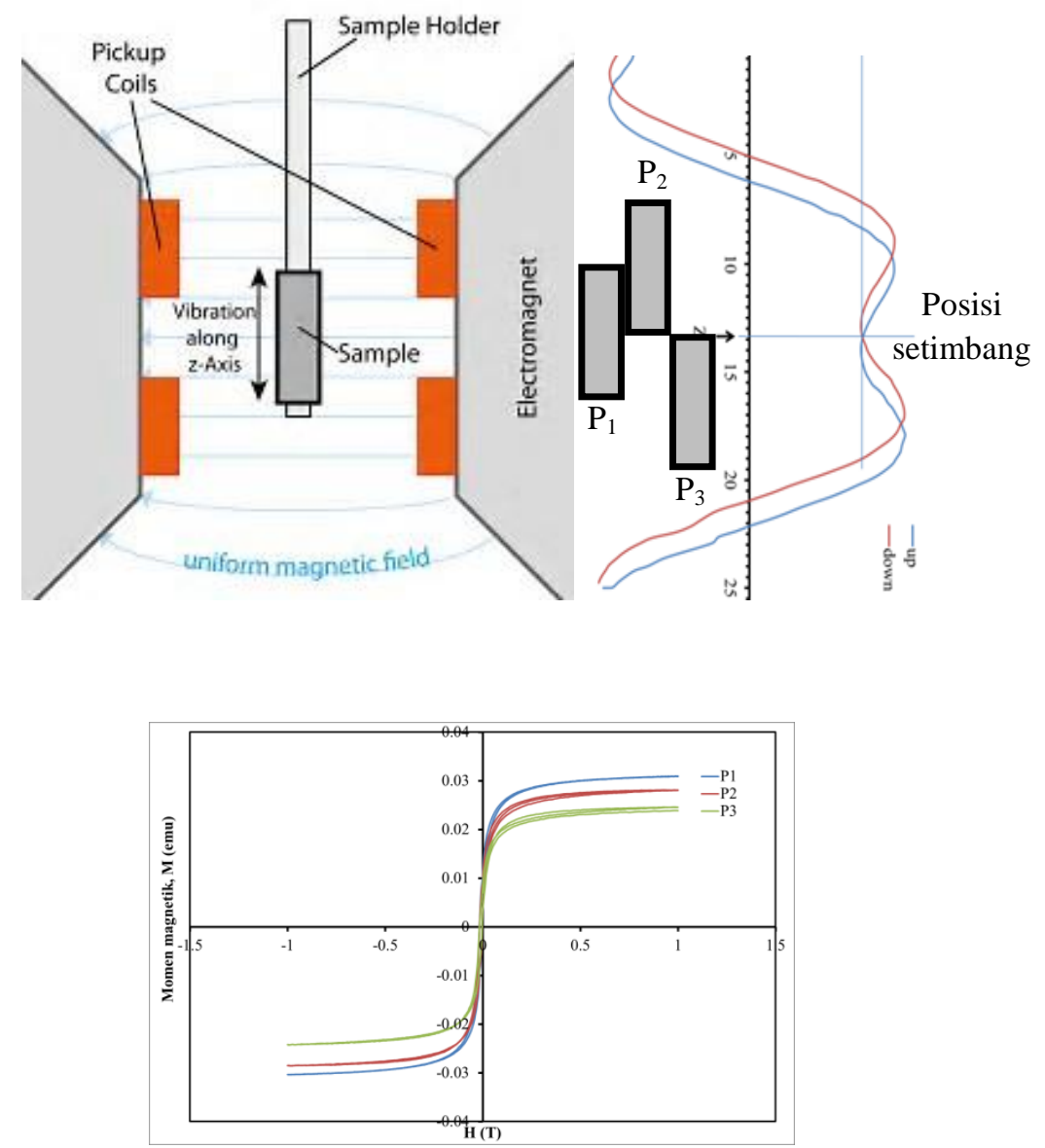

Gambar 6. Kurva histeresis sampel cair pada tiga posisi sekitar titik tengah

Untuk pengujian kedapat-ulangan pengukuran, disiapkan 7 sampel dengan volume sama yaitu 10 $\mu \mathrm{L}$ yang merupakan volume optimum seperti yang diperoleh pada pengukuran sebelumnya. Kurva histeresis dan massa sampel ditampilkan pada Gambar 7 dan Tabel 2. Dari data massa pada Tabel 2, penyiapan sampel memberikan kesalahan/penyimpangan massa sampel $\sim 3 \%$. Namun hasil pengukuran nilai momen magnetik menunjukkan penyimpangan yang lebih besar yaitu $\sim 4 \%$ yang dianalisis disebabkan oleh faktor posisi sampel dan kestabilan alat.

Faktor kestabilan alat dicoba dievaluasi dengan mengukur secara berulang pada sampel yang sama. Untuk itu dilakukan pengukuran dengan pengulangan tiap jam dengan kondisi dijaga tetap stabil. Kurva histeresis dan grafik analisis pengulangan ditampilkan pada Gambar 9.
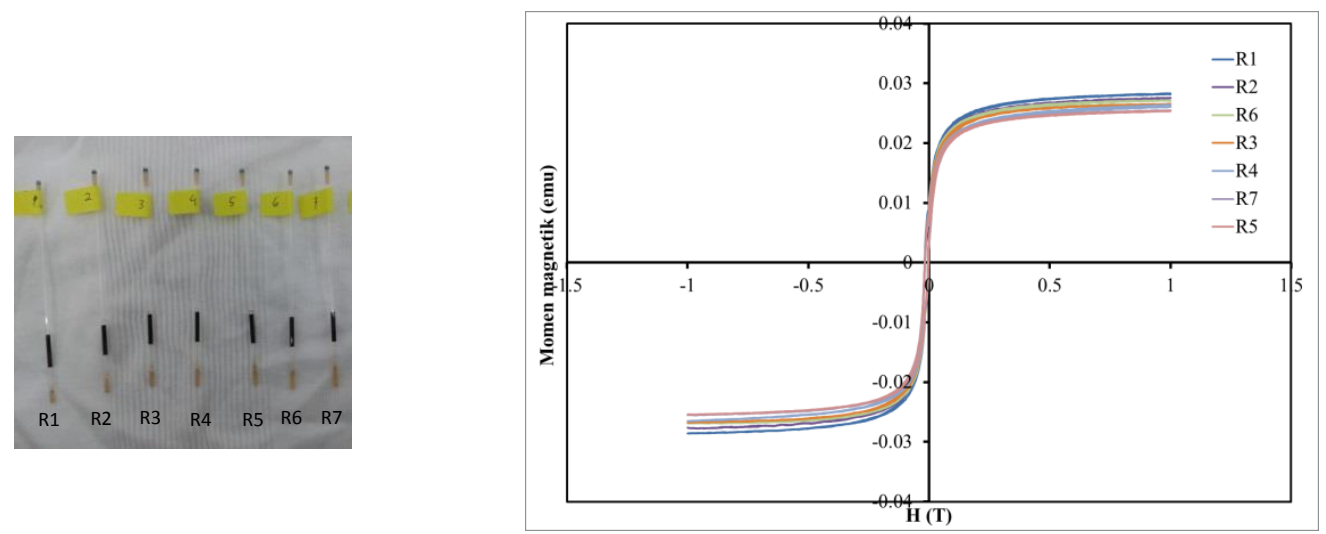

Gambar 7. Kurva histeresis sampel cair untuk pengulangan sampel 
Tabel 2. Data massa sampel cair dengan pengulangan sampel

\begin{tabular}{cccccccc}
\hline Sampel & $\boldsymbol{R}_{1}$ & $\boldsymbol{R}_{2}$ & $\boldsymbol{R}_{3}$ & $\boldsymbol{R}_{4}$ & $\boldsymbol{R}_{5}$ & $\boldsymbol{R}_{6}$ & $\boldsymbol{R}_{7}$ \\
\hline $\begin{array}{c}\text { Volume } \\
(\boldsymbol{\mu L})\end{array}$ & 10 & 10 & 10 & 10 & 10 & 10 & 10 \\
$\begin{array}{c}\text { Massa (mg) } \\
\text { (perhitungan) }\end{array}$ & 10,345 & 10,345 & 10,345 & 10,345 & 10,345 & 10,345 & 10,345 \\
$\begin{array}{c}\text { Massa (mg) } \\
\text { (terukur) }\end{array}$ & 10,19 & 10,27 & 10,34 & 10,12 & 10,55 & 10,35 & 10,21 \\
$\begin{array}{c}\text { Selisih massa } \\
(\mathbf{m g})\end{array}$ & 0,155 & 0,075 & 0,005 & 0,225 & $-0,205$ & $-0,005$ & 0,135 \\
\hline
\end{tabular}

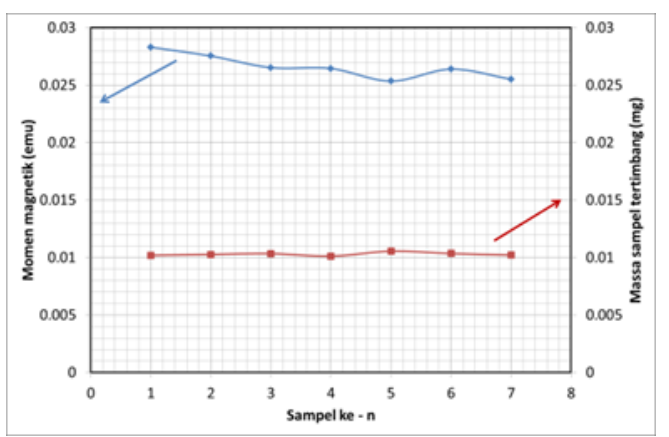

Gambar 8. Grafik perubahan momen magnetik dan massa sampel pada pengulangan sampel

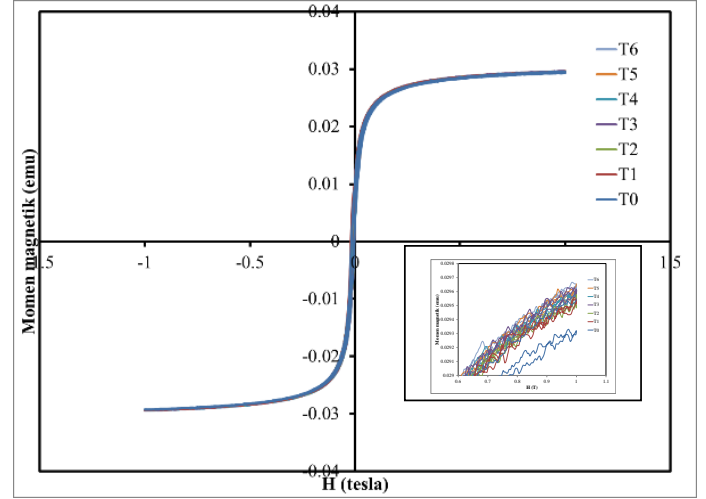

(a)

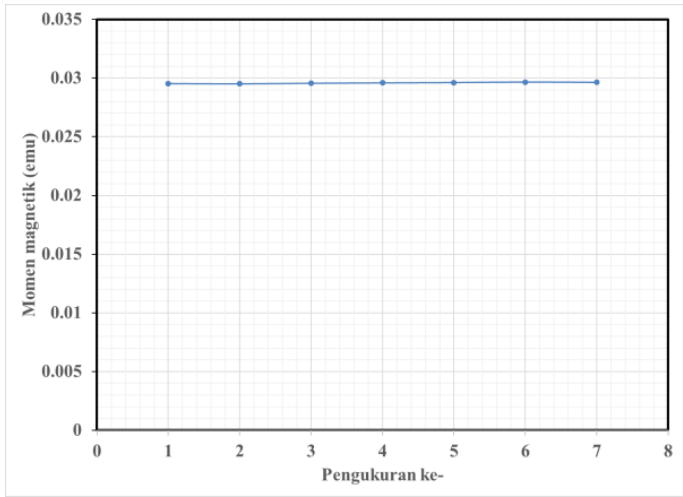

(b)

Gambar 9. Kurva histeresis (a) dan grafik analisis perubahan momen magnetik (b) pada pengulangan waktu pengukuran 

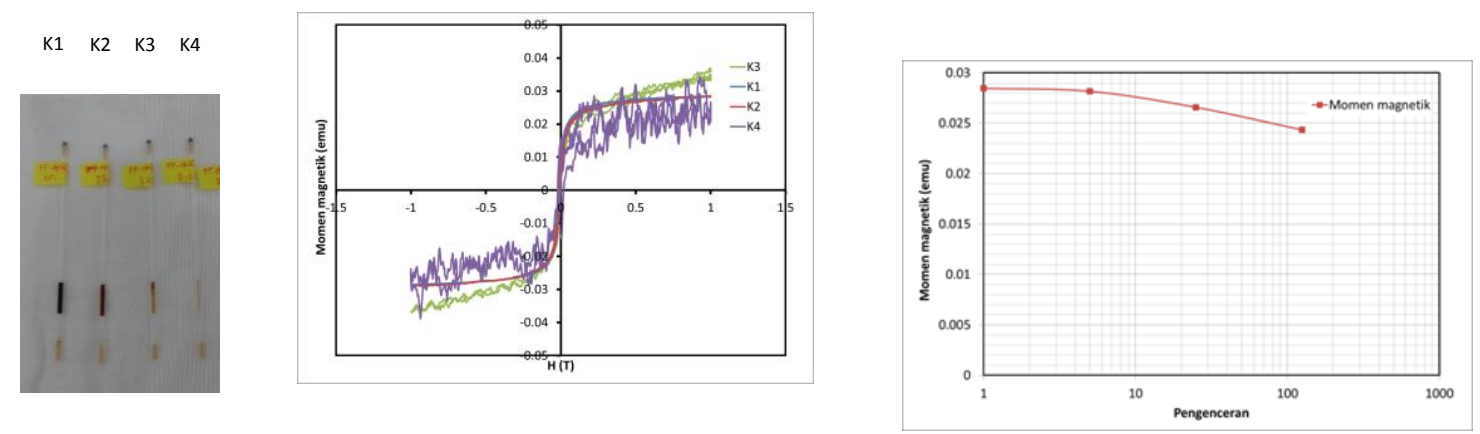

Gambar 10. Kurva histeresis dan grafik perubahan momen pada sampel dengan variasi konsentrasi

Data pada Gambar 9 menampilkan hasil pengukuran sebagai fungsi waktu dalam rentang waktu 6 jam dengan simpangan hasil pengukuran kurang dari $1 \%$. Data ini menunjukkan cukup stabilnya fasilitas VSM yang digunakan, serta kondisi sampel dan lingkungan selama pengukuran. Mengacu pada hasil analisis pengukuran berulang pada sampel yang berbeda pada paragraf sebelumnya, maka dapat disimpulkan bahwa kesalahan terbesar pengukuran lebih pada proses penyiapan sampel dan penempatan sampel. Pengamatan lebih jauh juga menunjukkan pengisian sampel cair dalam tabung kapiler dengan menggunakan micropipette dalam kondisi tekanan positif memberikan kesalahan yang lebih kecil dibanding dengan kondisi tekanan negatif. Hal ini terkait dengan sifat sampel/ferrofluid yang cukup kental (viscous), sehingga pemilihan mode tekanan positif diharapkan dapat meningkatkan akurasi pemipetan terutama untuk sampel dalam jumlah yang sangat kecil [9], [10].

Perubahan konsentrasi secara umum mengakibatkan perubahan bentuk kurva histeresis dan penurunan nilai momen magnetik seperti yang tergambarkan pada Gambar 10. Sampel cair $10 \mu \mathrm{L}$ hasil pengenceran $1 \mathrm{x}\left(K_{l}\right), 5 \mathrm{x}\left(K_{2}\right), 25 \mathrm{x}\left(K_{3}\right)$ dan $125 \mathrm{x}\left(K_{4}\right)$ diukur dan dianalisis. Pada dasarnya dalam sampel cair, nilai magnetisasi bahan akan ditentukan oleh fraksi magnetisasi nanopartikel magnetik yang bersifat ferromagnetik dan fraksi magnetisasi medium yang bersifat diamagnetik serta interaksi antara keduanya. Pengenceran akan meningkatkan jumlah fraksi air dalam sampel yang akan meningkatkan fraksi diamagnetik serta menurunkan kuat interaksi antar nanopartikel magnetik. Nanopartikel magnetik juga cenderung lebih dinamis dan random gerakannya sehingga kurva histeresis cenderung tidak stabil. Dari hasil pengukuran diperoleh penurunan nilai momen magnetik hingga $\sim 5 \%$ pada sampel hasil pengenceran $125 \mathrm{x}$ atau pada konsentrasi $0,332 \mathrm{mg} / \mathrm{mL}$. Pada pengenceran selanjutnya sampel cenderung lebih paramagnetik dan nilai saturasi magnetik menjadi sulit ditentukan.

\section{Kesimpulan}

Dari serangkaian pengukuran yang dilakukan diperoleh bahwa range volume optimal dengan hasil pengukuran yang masih bisa dipertanggungjawabkan adalah $10 \mu \mathrm{L}$ dengan posisi sampel setimbang serta berada dalam daerah antara pick-up coil. Sedangkan konsentrasi terkecil yang masih dapat diamati secara kuantitatif adalah sampel dengan konsentrasi $0,332 \mathrm{mg} / \mathrm{mL}$. Keakuratan penyiapan sampel dan penempatan sampel merupakan faktor utama yang akan menentukan kedapatulangan/keakuratan hasil pengukuran momen magnetik. Pada pengujian ini diperoleh kesalahan/penyimpangan massa sampel $\sim 3 \%$ dan penyimpangan momen magnetik total $\sim 4 \%$. Secara umum dapat disimpulkan bahwa pengukuran sampel cair akan memberikan hasil yang lebih baik bila digunakan mode tekanan positif pada saat memasukkan sampel cair dengan micropipette serta sampel sesegera mungkin diukur setelah preparasi.

\section{Ucapan Terima Kasih}

Penelitian ini merupakan bagian dari kegiatan DIPA-PSTBM 2017 dengan judul "Litbang BioNanomaterial untuk Aplikasi Kesehatan". Penulis menyampaikan terima kasih kepada manajemen PSTBM-BATAN atas dukungan dana yang diberikan dan kepada Dra. Grace Tj. Sulungbudi, M.Sc sebagai penanggung jawab kegiatan atas bimbingannya dalam ekperimen dan penulisan makalah ini. 


\section{Daftar Rujukan}

[1] A. Joseph and S. Mathew, "Ferrofluids: Synthetic Strategies, Stabilization, Physicochemical Features, Characterization, and Applications," ChemPlusChem, vol. 79, no. 10, pp. 1382-1420, 2014.

[2] B. Issa, I. M. Obaidat, B. A. Albiss, and Y. Haik, "Magnetic nanoparticles: Surface effects and properties related to biomedicine applications," Int. J. Mol. Sci., vol. 14, no. 11, pp. 21266$21305,2013$.

[3] N. Pérez, C. Moya, P. Tartaj, A. Labarta, and X. Batlle, "Aggregation state and magnetic properties of magnetite nanoparticles controlled by an optimized silica coating," J. Appl. Phys., vol. 121, no. 4, p. 44304, 2017.

[4] D. Mayer and P. Polcar, "A novel approach to measurement of permeability of magnetic fluids," PRZEGLAD ELEKTROTECHNICZNY Electr. Rev., vol. 88, no. 7, pp. 229-231, 2012.

[5] Z. Boekelheide and C. L. Dennis, "Artifacts in magnetic measurements of fluid samples," AIP $A d v$., vol. 6, no. 8, 2016.

[6] T. Friedrich, T. Lang, I. Rehberg, and R. Richter, "Spherical sample holders to improve the susceptibility measurement of superparamagnetic materials," Rev. Sci. Instrum., vol. 83, no. 4, 2012.

[7] Mujamilah et al., "Vibrating sample magnetometer (VSM) tipe oxford vsm1.2h," Pros. Semin. Nas. Bahan Magn. I, vol. di, pp. 77-81, 2000.

[8] M. C. Mascolo, Y. Pei, and T. A. Ring, "Room Temperature Co-Precipitation Synthesis of Magnetite Nanoparticles in a Large ph Window with Different Bases," Materials, vol. 6, no. 12 , pp. 5549-5567, 2013.

[9] K. Ewald, "Impact of Pipetting Techniques on Precission and Accuracy," Eppendorf Userguide, no. 20, pp. 1-4, 2015.

[10]M. Art, V. Dufey, U. Gast, I. Gligor, L. Koch, and R. Kubasch, "The Tip of the Iceberg: How Pipette Tips Influence Results,” Eppendorf Apl. Note, no. 354, pp. 1-22, Oktober 2016. 